\title{
THE POSITION OF A STANDARD OPTICAL COMPUTER MOUSE AFFECTS CARDIORESPIRATORY RESPONSES DURING THE OPERATION OF A COMPUTER UNDER TIME CONSTRAINTS
}

\author{
SHUNJI SAKO ${ }^{1,2}$, HIROMICHI SUGIURA ${ }^{1}$, HIRONORI TANOUE ${ }^{2,3}$, MAKOTO KOJIMA ${ }^{4}$, \\ MITSUNOBU KONO ${ }^{5}$, and RYOICHI INABA ${ }^{2}$
}

${ }^{1}$ Nagoya Isen School Corporation Vocational College, Aichi, Japan

Department of Physical Therapy

${ }^{2}$ Graduate School of Medicine, Gifu University, Gifu, Japan

Department of Occupational Health

${ }^{3}$ Aichi Kouseiren Asuke Hospital, Aichi, Japan

Department of Rehabilitation

${ }^{4}$ Gifu Junior College of Health Science, Gifu, Japan

Department of Rehabilitation

${ }^{5}$ Faculty of Health Sciences, Kinjo University, Ishikawa, Japan

Department of Occupational Therapy

\begin{abstract}
Objectives: This study investigated the association between task-induced stress and fatigue by examining the cardiovascular responses of subjects using different mouse positions while operating a computer under time constraints. Material and Methods: The study was participated by 16 young, healthy men and examined the use of optical mouse devices affixed to laptop computers. Two mouse positions were investigated: (1) the distal position (DP), in which the subjects place their forearms on the desk accompanied by the abduction and flexion of their shoulder joints, and (2) the proximal position (PP), in which the subjects place only their wrists on the desk without using an armrest. The subjects continued each task for 16 min. We assessed differences in several characteristics according to mouse position, including expired gas values, autonomic nerve activities (based on cardiorespiratory responses), operating efficiencies (based on word counts), and fatigue levels (based on the visual ana$\log$ scale - VAS). Results: Oxygen consumption $\left(\mathrm{VO}_{2}\right)$, the ratio of inspiration time to respiration time $\left(\mathrm{T}_{\mathrm{i}} / \mathrm{T}_{\text {total }}\right)$, respiratory rate $(\mathrm{RR})$, minute ventilation $(\mathrm{VE})$, and the ratio of expiration to inspiration $\left(\mathrm{Te} / \mathrm{T}_{\mathrm{i}}\right)$ were significantly lower when the participants were performing the task in the DP than those obtained in the PP. Tidal volume (VT), carbon dioxide output rates $\left(\mathrm{VCO}_{2} / \mathrm{VE}\right)$, and oxygen extraction fractions $\left(\mathrm{VO}_{2} / \mathrm{VE}\right)$ were significantly higher for the DP than they were for the PP. No significant difference in VAS was observed between the positions; however, as the task progressed, autonomic nerve activities were lower and operating efficiencies were significantly higher for the DP than they were for the PP. Conclusions: Our results suggest that the DP has fewer effects on cardiorespiratory functions, causes lower levels of sympathetic nerve activity and mental stress, and produces a higher total workload than the PP. This suggests that the DP is preferable to the PP when operating a computer.
\end{abstract}

Key words:

Computer operation, Mouse position, Cardiorespiratory response, Operating efficiency, Workplace stress, Computer fatigue

Received: November 26, 2013. Accepted: March 27, 2014.

Corresponding author: S. Sako, Department of Physical Therapy, Nagoya Isen School Corporation Vocational College, Nagoya Isen, 4-27-1, Meieki, Nakamura, Nagoya, Aichi 450-0002, Japan (e-mail: sako.shunji@isen.ac.jp). 


\section{INTRODUCTION}

Rapid advancements in information technology have increased the use of computers in the corporate setting, which has dramatically changed the characteristics of workers' duties. "The Survey on Technological Innovation and Labour (2008)" [1] indicates that $68.6 \%$ of computer users experience some variety of physical fatigue or pain. Among the computer users who reported fatigue or pain, eye fatigue/ pain was the most common complaint (90.8\%), followed by stiffness/pain in the neck and shoulders (74.8\%), and fatigue/pain in the lower back (26.9\%). The percentage of persons complaining about stiffness/pain in the neck and shoulders has increased since $2003(70.4 \%)$ [2].

Moreover, $34.8 \%$ of the workers in 2003 and $34.6 \%$ in 2008 responded that they experienced a certain level of mental fatigue and stress. Survey questions regarding the daily average consecutive work hours showed that $52.1 \%$ and $44.3 \%$ of workers reported using computers for longer than 4 hours per day in 2003 and 2008, respectively. In both years, it was reported that the percentage of workers who feel stressed increased as their daily or consecutive work hours became longer.

The increasing use of computers is believed to have caused computer-related disorders (CRDs), such as eye fatigue, stiff shoulders, upper extremity pain, lower back pain, and mental stress $[3,4]$. Factors that can contribute to these conditions include the setting of the computer screen, which affects working posture [5], operating the computer for extended periods [6-8], and tasks that require repetitive and monotonous motions [9-12]. Additionally, mental stress levels are known to increase with the duration of computer-related tasks. Mental stress affects autonomic nerve activity [13-16] in CRDs caused by tasks that are performed under time constraints (for example, to meet deadlines) [17-19] or require speedy performance [16]. Although computers are operated using keyboards, touchpads, and mouse devices, CRDs and computer arm syndrome can even be associated with tasks involving the use of a mouse, which are generally considered light work [20]. (Computer arm syndrome is a musculoskeletal disorder that typically manifests as pain in the upper extremities and the posterior region of the neck). The side of the upper extremity used to operate the mouse [8,21-24], differences in mouse positions [25,26], differences in the shape of the mouse [20,27-29], the speed of mouse use in detailed operations [30], and differences caused by the use of armrests [29] can all contribute to CRDs that arise from the use of a mouse.

However, these previous investigations of mouse-based activities have primarily focused on the association between operating a computer and musculoskeletal disorders and many of them have examined the relationship between muscular activity and task-induced stress based on electromyography data. In contrast, few studies have examined associations between operating a computer and task-induced stress based on cardiorespiratory responses. Consequently, there are no reports on the nature of cardiorespiratory responses to mouse use and position while operating a computer. Accordingly, this study was designed to investigate the association of mouse position with taskinduced stress and fatigue. In particular, we assessed how the body is affected by the differences in mouse position while operating a computer under time constraints. Our analysis involved examinations of cardiorespiratory functions, autonomic nerve activities, and operating efficiency.

\section{MATERIAL AND METHODS}

\section{Subjects}

The study was participated by 16 young, healthy men with an average age of 23.2 (standard deviation-SD $=6.4$ ) years, body height $-175.3(\mathrm{SD}=0.1) \mathrm{cm}$, bodyweight $-69.6(\mathrm{SD}=5.7) \mathrm{kg}$, and body mass index (BMI) - $22.7(\mathrm{SD}=2.5)$. Each of the subjects had experience in using personal computers, was right-handed or used a mouse with their right hand, and was not contraindicated for the measurement of expired gas 
levels. We excluded 7 subjects with upper extremity pain, shoulder pain, lower back pain, disabilities that were previously sustained in these areas, vision problems (including those that could be corrected with contact lenses), smoking habits, and sleep disorders.

\section{Experimental design}

Computer mouse tasks were performed in the function training room at the Department of Physical Therapy of Nagoya Isen School Corporation Vocational College. We placed laptop computers (HP 6720s, Hewlett-Packard, Bellevue, USA) and optical computer mouse devices (HP EY703AA, Hewlett-Packard) on top of the desks, which were set at the height of the olecranon region. We used office chairs without armrests for computer operators (ITOKI vertebra 340; $\mathrm{W} \times \mathrm{D} \times \mathrm{H}, 55.6 \times 47.5 \times 71 \sim 81 \mathrm{~cm}$; Itoki Corp., Osaka, Japan). The subjects performed the task while seated comfortably in front of a computer with height adjustable chairs that were set to allow $90^{\circ}$ of knee flexion and 2 types of motion range of the shoulder joint. The subjects were allowed to place their left arms on or off the table according to their own style. Each personal computer was set up at the position where the subject felt most comfortable, using an approximately $70 \mathrm{~cm}$ distance from the subject's eyes as a reference. The room temperature was set at $24^{\circ} \mathrm{C}$.

\section{Setting the position of the mouse}

The mouse devices were set up in 2 positions:

- the distal position (DP, Figure 1a), in which the subjects place their shoulder joints in a neutral position and forearms at a $15^{\circ}$ abduction and flexion;

- the proximal position (PP, Figure 1b), in which the subjects place their shoulder joints in a neutral position and forearms at a $0^{\circ}$ abduction and flexion with the elbow joints at $90^{\circ}$, while leaving the olecranon area on the body side and only resting the wrist area on the desk, without the use of an armrest.
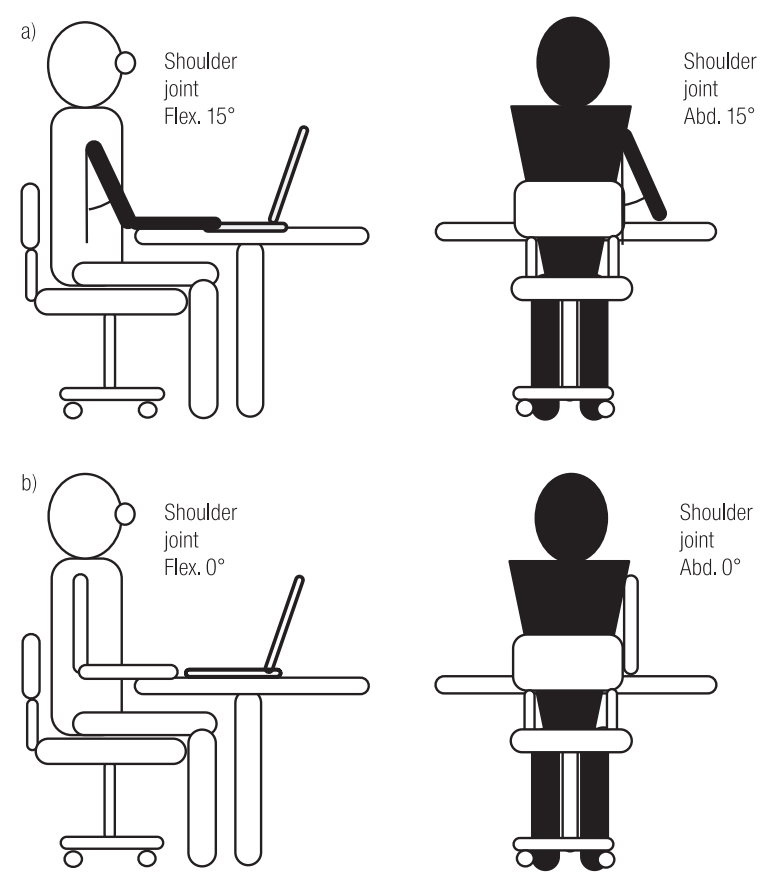

Flex. - flexion; Abd. - abduction.

Fig. 1. Positions of the mouse investigated in this study: a) distal position and b) proximal position

\section{Task and procedure}

The subjects placed both upper extremities at the sides of their body and began the task when they were in a relaxed state. They were instructed to write the alphabet from "a" to "z", using the mouse to draw each individual letter (Figure 2). The subjects were told to write small letters only, and to repeat the alphabet throughout the duration of each 16-min session of the experiment. A trial session was conducted for $1 \mathrm{~min}$ prior to the beginning of the experimental procedure, to train the participants in the exact nature of the task. After the experimental procedure began, the subjects received repeated verbal reminders to continue writing the alphabet as thoroughly and quickly as possible. These reminders were designed to place the subjects under stress, and were repeated for the full 16-min duration of each experimental session. To recover from fatigue, the participants were given a 10-min break between each session of the task. Each mouse position was maintained for the full duration of an experimental 


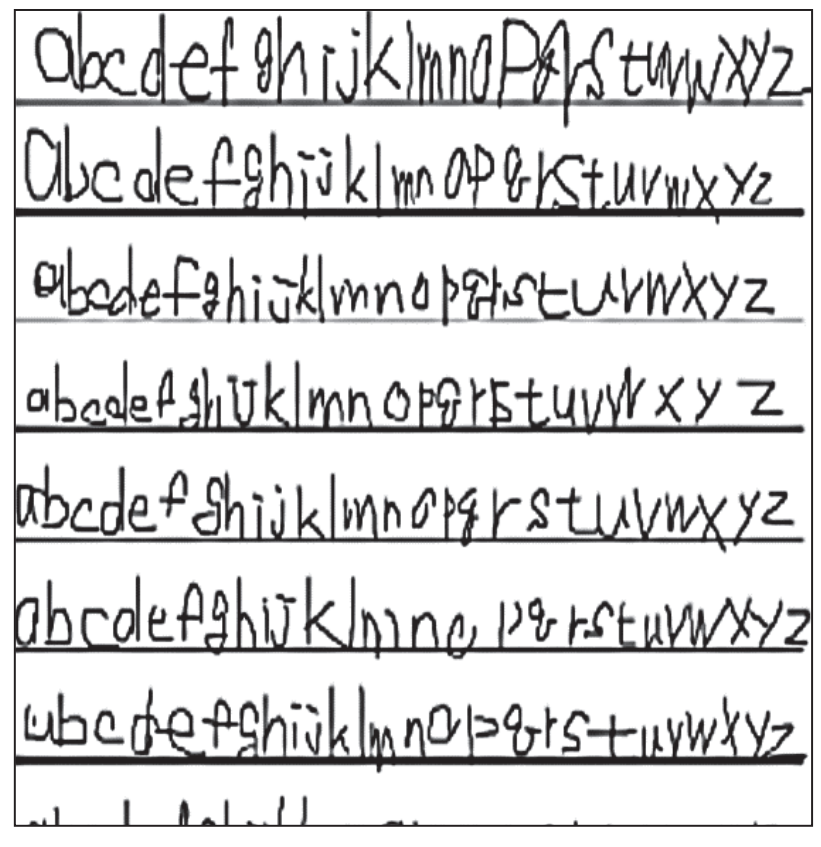

Fig. 2. Workload: subjects were required to continue writing the alphabets

session, and measurements were taken for the different positions during consecutive sessions. The sequence of mouse positions (distal or proximal) was randomized for each subject to keep their workloads balanced, and to prevent bias related to order effects, which could otherwise arise from increasing levels of fatigue after multiple 16-min experimental runs. Measurements of expired gas and heart rate were taken for $60 \mathrm{~s}$ at rest before the beginning of each task, and continued until the task was completed.

We used the visual analog scale (VAS) chart [31] based on the Guideline for Clinical Evaluation of Anti-Fatigue (December 22, 2011) that was prepared by the Japanese Society of Fatigue Science to assess subjective levels of mental and physical fatigue. VAS evaluations were performed at the end of the 1st 8 min of the task (the 1st half) and the end of the 2nd 8 min of the task (the 2nd half).

\section{Respiratory metabolism}

We used a respiratory metabolism measurement device (Aeromonitor AE-300S, Minato Medical Science, Co.,
Ltd., Osaka, Japan) to analyze expired gas and measure the expiratory flow rate consecutively using the breathby-breath method. A Dell Latitude AEC-3000 (Round Rock, USA) was connected to the analyzer and used to record and evaluate the measured values. After disinfecting the mask that was used for the measurement with alcohol-wetted cotton balls, we placed it firmly on the subjects' nose and mouth and measured their breathing at rest for $60 \mathrm{~s}$ prior to the beginning of the task.

Subsequently, the subjects began the letter writing task using a mouse. Measurements were continued throughout the 16-min length of the task. For each mouse position (distal and proximal), we measured minute ventilation $\left(\mathrm{V}_{\mathrm{E}}\right)$, tidal volume $\left(\mathrm{V}_{\mathrm{T}}\right)$, respiratory rate $(\mathrm{RR})$, oxygen consumption $\left(\mathrm{VO}_{2}\right)$, the oxygen extraction ratio $\left(\mathrm{VO}_{2} / \mathrm{V}_{\mathrm{E}}\right)$, the carbon dioxide output rate $\left(\mathrm{VCO}_{2} / \mathrm{V}_{\mathrm{E}}\right)$, the ratio of inspiration time to respiration time $\left(\mathrm{T}_{\mathrm{i}} / \mathrm{T}_{\text {total }}\right)$, and the ratio of expiration to inspiration $\left(\mathrm{T}_{\mathrm{e}} / \mathrm{T}_{\mathrm{i}}\right)$.

\section{Autonomic nerve activity}

Using a heart rate monitor (RS 800, Polar Electro, Kempele, Finland), we obtained the average heart rate (HR) from beat-to-beat intervals (R-R intervals) every $60 \mathrm{~s}$, and then conducted a frequency domain analysis based on the R-R intervals. A transmitter that measured the heart rate was attached to each subject's anterior chest area (at the papilla level), which had been disinfected with alcohol-wetted cotton balls in advance. The transmitter itself was attached with disposable electrodes (Metz Inc., Tokyo, Japan).

To assess the heart rate at rest, measurements were conducted for $60 \mathrm{~s}$ immediately before the task performance. Subsequently, the subjects began the letter writing session, and measurements were continued until the end of each session. Results were used to calculate the average ratio of low frequency (LF) components to high frequency (HF) components. LF components are believed to reflect sympathetic nerve functions, and high frequency (HF) 
components are believed to reflect parasympathetic nerve functions. These derived quantities were then compared to the autonomic nerve activity during the 1 st and the 2 nd half of the task sessions.

\section{Subjective ratings of perceived exertion}

At the end of the 1st and 2nd half of the task sessions, we used VAS to assess subjective evaluations of the degree of fatigue associated with each position of the mouse. The subjects were asked to draw a line almost $100 \mathrm{~mm}$ in length, which ranged from the left end (representing the best feeling that the participant had ever experienced previously, when he felt almost no fatigue) to the right end (representing the worst feeling the subject had ever experienced previously, when he felt so tired that he could not do anything). Afterwards, we measured the length of the line that the subject had drawn, and used this distance as a subjective evaluation.

\section{Workload}

For each mouse position, workloads were calculated based on the number of alphabets that the subjects had written during the task (Figure 2).

\section{Ethics}

Permission for this investigation was received from the Nagoya Isen School Corporation Vocational College. The study also received approval from the Gifu Junior College of Health Science Ethics Committee (H24-4), and was conducted in accordance with the Declaration of Helsinki. A written consent had been provided by all participants before the study began.

\section{Statistics}

We used 1-way repeated measures analysis of variance (ANOVA) to assess chronological changes in each of the cardio-respiratory index values, according to mouse position. Paired t-tests were used to assess the subjective VAS evaluations of fatigue, and also the autonomic nervous activities measured during the 1st and 2nd half of the sessions. Two-way repeated measures ANOVA was employed to assess chronological changes in each respiratory index value, according to mouse position. IBM SPSS Statistics Base 19 software (IBM SPSS, Chicago, USA) was used for all statistical processing, and the level of significance was set at $\mathrm{p}<0.05$.

\section{RESULTS}

\section{Respiratory metabolism}

Throughout the duration of the tasks, the DP was associated with significantly lower respiration rates (RR) than the PP ( $p=0.006$, Figure $3 a$ ). However, highly similar changes in respiratory responses were observed in both DP and PP assessments; RR increased significantly ( $p<0.0001)$ during the 1st min after the subjects began the task, and thereafter remained approximately constant. For the entire duration of the task, the DP was associated with higher $\mathrm{V}_{\mathrm{T}}$ than the PP, although the difference was not statistically significant ( $p=0.224$, Figure $3 b$ ). In both the DP and PP assessments, $\mathrm{V}_{\mathrm{T}}$ declined significantly during the 1 st min of the task sessions ( $p=0.009)$, and then gradually rose towards the level observed when the subjects were at rest.

Throughout the task, the DP was associated with a significantly greater $V_{E}$ than the $P P(p=0.002$, Figure $3 c)$. In both the DP and $\mathrm{PP}$ assessments, $\mathrm{V}_{\mathrm{E}}$ increased significantly during the 1st min of the task $(p<0.001)$, and remained constant. For the duration of the task, the DP was associated with a significantly lower $\mathrm{VO}_{2}$ than the PP ( $\left.\mathrm{p}=0.027\right)$. In both assessments, $\mathrm{VO}_{2}$ increased significantly during the 1 st min of the task ( $p=0.004)$, then declined, and finally increased again during the 2 nd half of the task.

Throughout the task, the DP was associated with a significantly greater $\mathrm{VO}_{2} / \mathrm{V}_{\mathrm{E}}$ ratio than the $\mathrm{PP}(\mathrm{p}=0.021$, Figure 3e). In both assessments, this ratio declined 

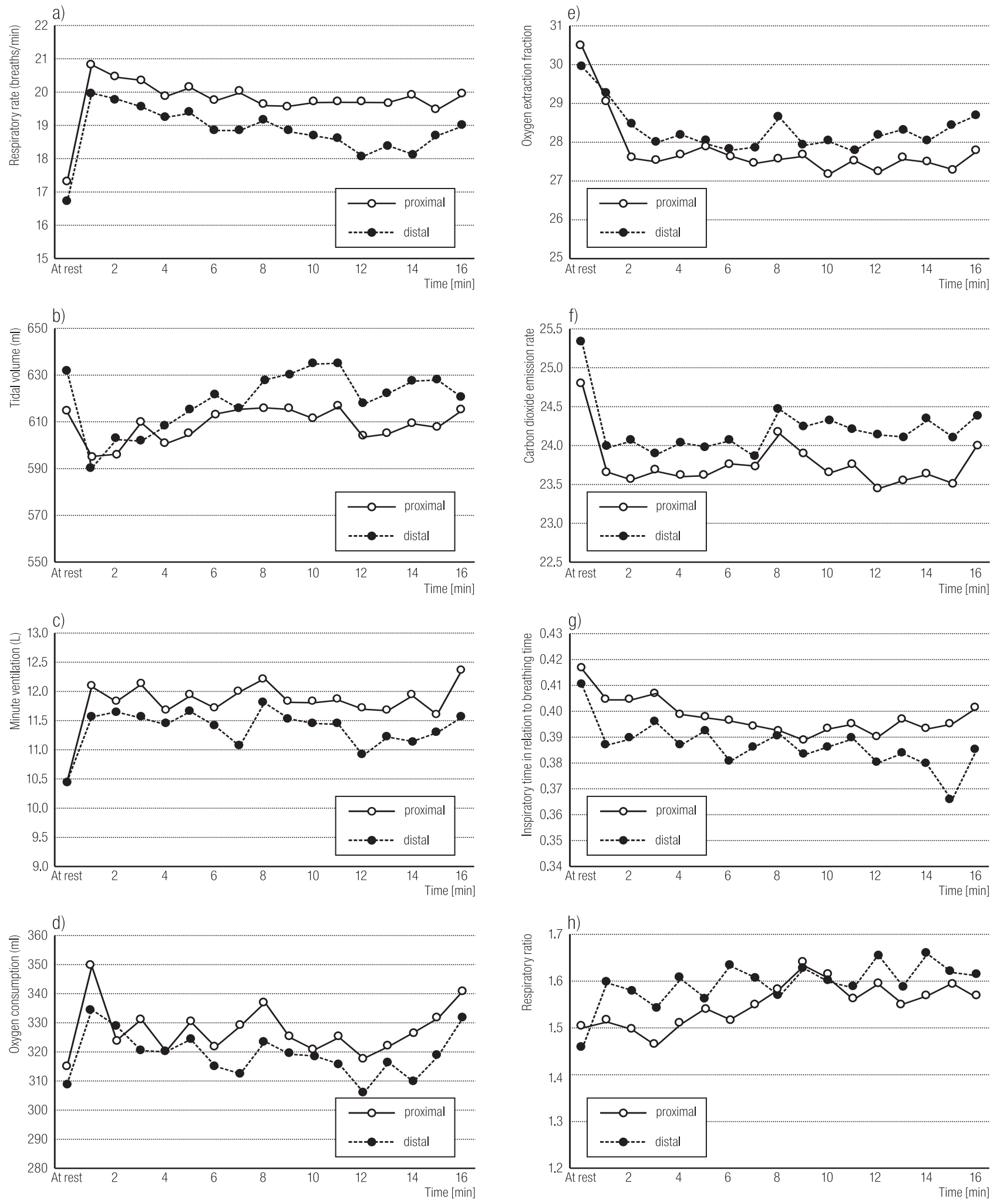

Fig. 3. Differences in cardiorespiratory responses according to mouse position 

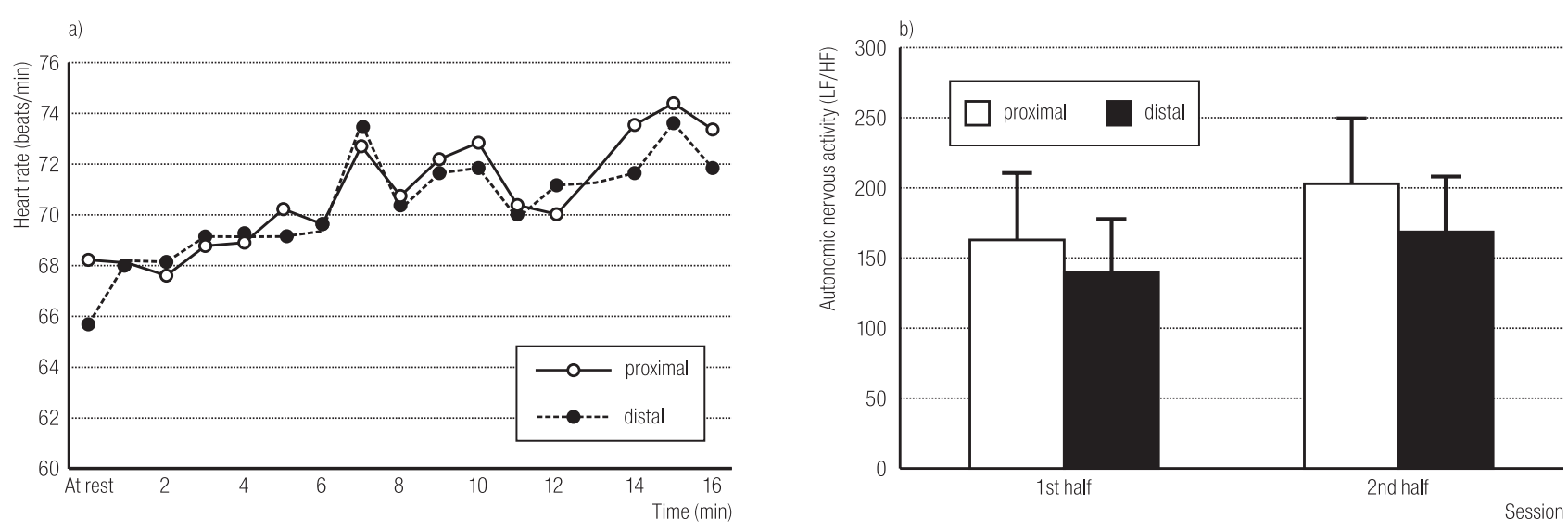

Fig. 4. Differences in (a) heart rate and (b) autonomic nerve activity according to mouse position

significantly for the task during the 1st min of the task ( $p=0.001$ ), continued to decline for another $3 \mathrm{~min}$, and finally became approximately constant.

For the duration of the task, the DP was associated with a significantly greater $\mathrm{VCO}_{2} / \mathrm{V}_{\mathrm{E}}$ ratio than the PP $(p=0.043$, Figure $3 f)$. In both assessments, this ratio declined significantly during the 1 st $\min (\mathrm{p}<0.0001)$, and then remained constant.

Throughout the task, the DP was associated with a significantly lower $\mathrm{T}_{i} / \mathrm{T}_{\text {total }}$ ratio than the PP ( $\mathrm{p}<0.0001$, Figure $3 \mathrm{~g}$ ). In both assessments, this ratio declined significantly during the 1 st min of the task $(\mathrm{p}=0.001)$, and maintained a low value thereafter.

Finally, for the duration of the task, the DP was associated with a significantly higher $\mathrm{T}_{\mathrm{e}} / \mathrm{T}_{\mathrm{i}}$ than the PP $(p=0.005$, Figure $3 h)$. In the DP assessment, $T_{e} / T_{i}$ increased significantly during the 1 st min of the task ( $p=0.044)$. In the PP assessment, however, this ratio increased gradually.

\section{Heart rate}

The heart rate (HR) of the subjects increased as the task progressed, and was significantly greater in the 2 nd half of the task than in the 1 st half $(\mathrm{p}<0.0001)$. However, no significant difference was observed between the DP and PP sessions ( $p=0.899$, Figure 4a).

\section{Autonomic nerve activity}

Mean LF/HF values reflect autonomic nerve activity during each session. For the DP assessment, the mean LF/HF values equaled 141.03 (standard error-SE: 38.47) and 167.78 (SE: 39.36) during the 1st and 2nd half of the session, respectively. For the PP assessment, the corresponding values were 162.33 (SE: 47.75) and 202.94 (SE: 46.58). For both mouse positions, LF/ $\mathrm{HF}$ was significantly greater during the 2 nd half of the task than it was during the 1st half of the task ( $p=0.004$ for PP, $p=0.009$ for DP). Furthermore, LF/HF tended to be lower during the 2nd half of the DP assessment than during the 2nd half of the PP assessment, although the difference was not statistically significant ( $p=0.057$, Figure $4 b)$.

\section{Subjective ratings of perceived exertion}

The average VAS values in the DP assessments were 4.45 (SE: 0.51$) \mathrm{cm}$ and 5.89 (SE: 0.52) $\mathrm{cm}$ for the 1st and 2nd half of the sessions, respectively. The corresponding values for the PP assessment were 4.20 (SE: 0.51) cm and 6.06 (SE: 0.66$) \mathrm{cm}$. In both assessments, the VAS values increased significantly from the 1 st to the 2 nd half of the task ( $p=0.001$ for PP, $p=0.001$ for DP). However, the VAS values did not differ significantly according to the mouse position ( $p=0.937$, Figure 5). 


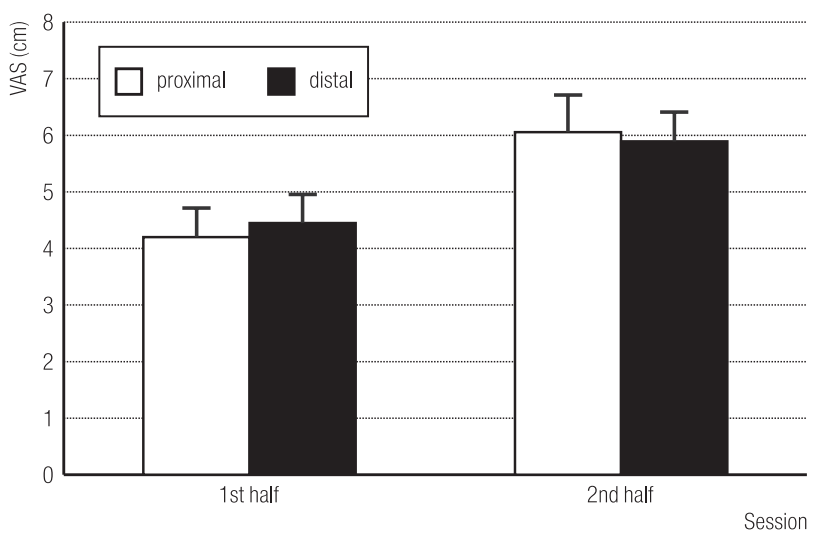

Fig. 5. Visual analog scale (VAS) according to mouse position

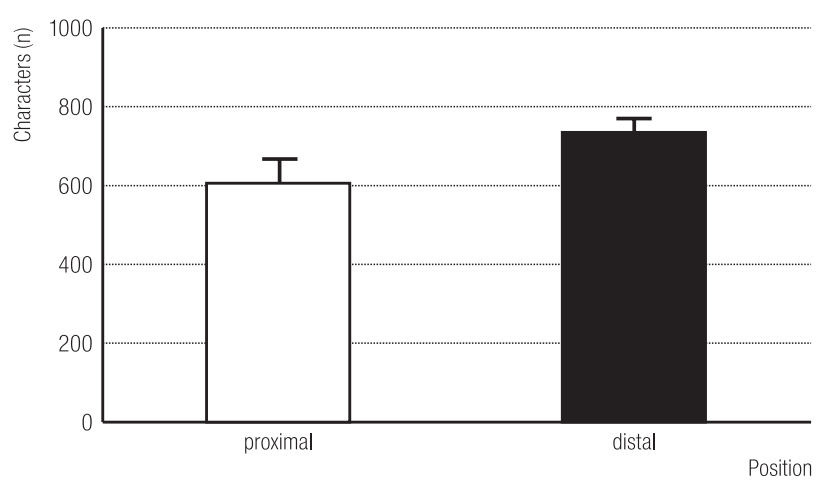

Fig. 6. Workload according to mouse position

\section{Workload}

The average workloads (the average number of alphabets written by the participants) were 724.72 (SE: 62.88) and 604.27 (SE: 45.11) for the DP and PP assessments, respectively. Accordingly, the average workload for the DP was approximately $19.9 \%$ higher than that for the PP, which constituted a significant difference $(p=0.041$, Figure 6).

\section{DISCUSSION}

The present study aimed to examine the association of computer mouse position with task-induced stress and fatigue. We measured cardiorespiratory responses and autonomic nerve activities while the subjects were performing simple consecutive, time-constrained computer tasks using different mouse positions. Throughout this experiment, we sought to obtain information that could motivate improvements to the computer work environment.

Notably, we found that operating a computer under time constraints caused changes to the respiratory function immediately after the task began, and that the level of mental stress increased as the subjects continued their tasks. Grossman [32] has stated that changes in respiratory patterns provide a good indicator of anxiety and stress, because respiratory functions are believed to be accelerated by stress-related stimuli, in addition to other factors such as physical exertion and exercise.

We further found that respiratory responses changed as soon as the tasks began. $\mathrm{V}_{\mathrm{T}}, \mathrm{VO}_{2} / \mathrm{V}_{\mathrm{E}}, \mathrm{VCO}_{2} / \mathrm{V}_{\mathrm{E}}$, and $\mathrm{Ti} / \mathrm{T}_{\text {total }}$ declined, while $\mathrm{RR}, \mathrm{V}_{\mathrm{E}}, \mathrm{VO}_{2}$, and $\mathrm{T}_{\mathrm{e}} / \mathrm{T}_{\mathrm{i}}$ increased. These results suggest that increased RR may compensate for declines in $\mathrm{V}_{\mathrm{T}}, \mathrm{VO}_{2} / \mathrm{V}_{\mathrm{E}}$, and $\mathrm{VCO}_{2} / \mathrm{V}_{\mathrm{E}}$. Moreover, declines in $\mathrm{T}_{\mathrm{i}} / \mathrm{T}_{\text {total }}$ and high $\mathrm{T}_{\mathrm{e}} / \mathrm{T}_{\mathrm{i}}$ values indicate that the subjects' respiration transitioned to shallow, fast breathing with an inspiration time that was short in comparison with the expiration time. We believe that this shows changes in respiration patterns that were caused by acceleration of the inspiratory flow, to increase oxygen intake as soon as the task began.

Similar responses were observed for both mouse positions that were examined, and they can be considered as a typical example of respiratory response patterns in simple computer-based tasks that require the use of a mouse under time constraints. Moreover, comparing the mouse positions showed that $\mathrm{V}_{\mathrm{E}}, \mathrm{VO}_{2}, \mathrm{~T} / \mathrm{T}_{\mathrm{i}}, \mathrm{VO}_{2} / \mathrm{V}_{\mathrm{E}}$, and $\mathrm{VCO}_{2} / \mathrm{V}_{\mathrm{E}}$ were significantly lower for the PP assessments than for the DP assessments, while $T_{i} / T_{\text {total }}$, and RR were significantly higher for the PP assessments.

Some studies have reported that tasks performed under mental stress (such as arithmetic calculations and cold temperature stimuli) affect autonomic nerve activity. In turn, changes in autonomic nerve activity are reflected by cardiorespiratory responses, most specifically increased heart and respiratory rates in many cases [33]. 
These studies have noted significant increases in RR, $\mathrm{V}_{\mathrm{E}}$, and inspiratory flow during memory recollection tasks, which have been particularly strong for $\mathrm{V}_{\mathrm{E}}$ and inspiratory flow [34]. Furthermore, these studies have demonstrated that $\mathrm{HR}, \mathrm{RR}$, and $\mathrm{VO}_{2}$ increase when the subjects are overwhelmed with tasks involving calculations $[35,36]$. In the present study, the declines in $\mathrm{V}_{\mathrm{T}}$, $\mathrm{VO}_{2} / \mathrm{V}_{\mathrm{E}}, \mathrm{VCO}_{2} / \mathrm{V}_{\mathrm{E}}$, and $\mathrm{T}_{\mathrm{i}} / \mathrm{T}_{\text {total }}$ as well as the increases in $\mathrm{RR}, \mathrm{V}_{\mathrm{E}}, \mathrm{VO}_{2}$, and $\mathrm{T}_{\mathrm{e}} / \mathrm{T}_{\mathrm{i}}$ are believed to occur due to cardiorespiratory responses to task-induced stress. Moreover, our results suggest that tasks performed in the PP caused more stress than those performed in the DP. It is particularly interesting that the differences in respiratory functions are evident even with changes in mouse position. Based on our results, we believe that the simple, continuous task of writing the alphabet (which involved clicking and dragging operations) caused measurable mental stress.

The results also show that HR increased gradually as soon as the subjects began the task. This study used a general method because evaluation of autonomic nerve activity based on the frequency analysis of heart rate variability is both simple and non-invasive [37]. Our frequency analysis of heart rate variability determined that the LF/HF ratio was high throughout the task, particularly during its 2 nd half. This indicates that the subjects experienced sympathetic nerve activation as the task progressed. Indeed, we believe that the simple computer task under time constraints leads to autonomic nerve activation, and particularly sympathetic nerve activation. This response was observed for both mouse positions, and sympathetic nerve activity was greater in the 2nd half of the PP assessment than it was during the 2nd half of the DP assessment.

Additionally, the total workload was significantly higher for tasks performed in the DP than for those performed in the PP. The VAS values were significantly elevated for both mouse positions. However, VAS did not differ significantly between the DP and PP. This suggests that there is a divergence between subjective fatigue and the physiological response of the body. It also remains possible that VAS was affected by the subjects' relative unfamiliarity with the task, or that the subjects failed to adequately represent their physiological and mental fatigue. Further investigation would be needed to fully resolve these issues. Based on the results described above, it appears that the DP has fewer effects on cardiorespiratory functions, causes lower levels of sympathetic nerve activity and mental stress, and produces a higher total workload than the PP. This suggests that the distal configuration is preferable to the proximal configuration when operating a computer.

Using a muscular activity analysis, Karlqvist et al. [38] have reported that task-induced fatigue varies according to the body type and mouse position when operating a computer. Indeed, they observed significantly more frequent muscular activity among persons who have a short stature with narrow shoulders. Regarding the mouse position, the authors stated that a $10-12^{\circ}$ shoulder joint flexion and a $21-33^{\circ}$ abduction position is the most comfortable configuration when performing tasks. This configuration is similar to the DP that we investigated.

In the present study, the majority of the participants using the distal configuration positioned their forearms on the desk or used armrests. Karlqvist et al. also found that the level of muscular activity is the greatest in the position with $34^{\circ}$ of abduction, suggesting that this position is not preferable. Moreover, it was also demonstrated that placing forearms on a desk or using armrests is associated with a lower level of shoulder muscle activity than not using armrests or the desktop for forearm support. Therefore, the differences that we observed in cardiorespiratory responses according to mouse position indicate that there is a connection between background and muscle activities, suggesting that this is an important topic for future research. As mentioned previously, our results suggest that respiratory responses are not only caused by tasks or 
exercise, but also the configuration of the environment in which the task or exercise is completed, for example, the position of the mouse while operating a computer.

For tasks performed under time constraints, our results indicated that cardiopulmonary function and task-induced stress vary according to mouse position. Although the present study was performed in a limited laboratory environment, our results provide evidence that could lead to more desirable configurations of work environments, such as more optimal selection of mouse position in consideration of task-induced stress and fatigue during computer operation.

\section{Limitations of the study}

The significant results that were obtained in this study highlight that cardiorespiratory responses vary according to mouse position during simple, continuous operation of a computer under time constraints. However, it is essential to conduct future investigations on the underlying explanation of these respiratory responses.

Muscular activity is believed to be one of the many factors that contribute to stress when operating a computer. Therefore, it remains necessary to examine how muscle activity levels and patterns required may vary according to the type of mouse that is used. While a standard optical mouse was used for this study, other types of mouse devices should be investigated for reference.

In this study, we obtained consistent results by designing a simple task: continuously writing the alphabet. However, it remains necessary to investigate the validity of the task set up for this study, as well as other types of tasks that reflect different aspects of computer use.

Additionally, this study was performed in a laboratory over a short period of time (16 min), and had a limited number of subjects, all of whom were young and male. Therefore, it remains essential to examine different task durations and a wider range of subjects who use computers in professional settings. These limitations have prompted us to design more effective studies in the future.

\section{CONCLUSIONS}

The position of the mouse is one of the important conditions when operating a computer. In the present study, we examined whether mouse position could increase operating efficiency by assessing cardiorespiratory functions, autonomic nerve activity, and operating efficiency while the participants were operating a computer under time constraints. In particular, we focused on physiological responses to the computer operators' mental and physical activities.

Our results showed increased levels of task-induced stress while using a mouse, as evidenced by an increase in cardiorespiratory responses $\left(\mathrm{RR}, \mathrm{V}_{\mathrm{E}}, \mathrm{VO}_{2}\right.$, and $\left.\mathrm{HR}\right)$ and by accelerated sympathetic nerve activity. We found that cardiorespiratory responses, work capacity, and stress conditions varied according to mouse position. Our results indicate that the DP, in which the forearms are placed on the desk, is preferable to the PP, in which only the wrist area is placed on the desk, without using an armrest. Our findings suggest that the position of the mouse affects the cardiopulmonary function and work place stress. Therefore, paying greater attention to mouse position could lead to an improved work environment.

\section{ACKNOWLEDGEMENTS}

We would like to express our heartfelt gratitude to all individuals at the Nagoya Isen School Corporation Vocational College, who have assisted us in the use of research devices, and who have provided the resources for carrying out this study.

\section{REFERENCES}

1. Survey on Technological Innovation and Labour. Tokyo: Statistics and Information Department, Minister's Secretariat, Ministry of Health, Labour and Welfare; 2008.

2. Survey on Technological Innovation and Labour. Tokyo: Statistics and Information Department, Minister's Secretariat, Ministry of Health, Labour and Welfare; 2003. 
3. Rosenfield M. Computer vision syndrome: A review of ocular causes and potential treatments. Ophthalmic Physiol Opt. 2011;31(5):502-15, http://dx.doi.org/10.1111/j.14751313.2011.00834.x.

4. Burgess RA, Thompson RT, Rollman GB. The effect of forearm posture on wrist flexion in computer workers with chronic upper extremity musculoskeletal disorders. BMC Musculoskelet Disord. 2008;9:47, http://dx.doi. org/10.1186/1471-2474-9-47.

5. Berkhout AL, Hendriksson-Larsén K, Bongers P. The effect of using a laptop station compared to using a standard laptop PC on the cervical spine torque, perceived strain and productivity. Appl Ergon. 2004;35(2):147-52, http://dx.doi. org/10.1016/j.apergo.2003.11.008.

6. Mork PJ, Westgaard RH. The influence of body posture, arm movement, and work stress on trapezius activity during computer work. Eur J Appl Physiol. 2007;101(4):445-56, http://dx.doi.org/10.1007/s00421-007-0518-4.

7. Wu S, He L, Li J, Wang J, Wang S. Visual display terminal use increases the prevalence and risk of work-related musculoskeletal disorders among Chinese office workers: A crosssectional study. J Occup Health. 2012;54(1):34-43, http:// dx.doi.org/10.1539/joh.11-0119-OA.

8. Tornqvist EW, Hagberg M, Hagman M, Risberg EH, Toomingas A. The influence of working conditions and individual factors on the incidence of neck and upper limb symptoms among professional computer users. Int Arch Occup Environ Health. 2009;82(6):689-702, http://dx.doi.org/10.1007/ s00420-009-0396-7.

9. Lundberg U. Psychophysiology of work: Stress, gender, endocrine response, and work-related upper extremity disorders. Am J Ind Med. 2002;41(5):383-92, http://dx.doi.org/10.1002/ ajim.10038.

10. Fuller JR, Lomond KV, Fung J, Côté JN. Posture-movement changes following repetitive motion-inducedshoulder muscle fatigue. J Electromyogr Kinesiol. 2009;19(6):1043-52, http://dx.doi.org/10.1016/j.jelekin.2008. 10.009 .
11. Crenshaw AG, Djupsjöbacka M, Svedmark A. Oxygenation, EMG and position sense during computer mouse work. Impact of active versus passive pauses. Eur J Appl Physiol. 2006;97(1): 59-67, http://dx.doi.org/10.1007/s00421-006-0138-4.

12. Bloemsaat JG, Meulenbroek RG, van Galen GP. Differential effects of mental load on proximal and distal arm muscle activity. Exp Brain Res. 2005;167(4):622-34, http://dx.doi. org/10.1007/s00221-005-0066-2.

13. Strøm V, Røe C, Knardahl S. Work-induced pain, trapezius blood flux, and muscle activity in workers with chronic shoulder and neck pain. Pain. 2009;144(1-2):147-55, http://dx.doi. org/10.1016/j.pain.2009.04.002.

14. Flodgren G, Heiden M, Lyskov E, Crenshaw AG. Characterization of a laboratory model of computer mouse use - applications for studying risk factors for musculoskeletal disorders. Appl Ergon. 2007;38(2):213-8, http://dx.doi. org/10.1016/j.apergo.2006.03.001.

15. Schleifer LM, Spalding TW, Kerick SE, Cram JR, Ley R, Hatfield BD. Mental stress and trapezius muscle activation under psychomotor challenge: A focus on EMG gaps during computer work. Psychophysiology. 2008;45(3):356-65, http://dx.doi.org/10.1111/j.14698986.2008.00645.x.

16. Wang Y, Szeto GP, Chan CC. Effects of physical and mental task demands on cervical and upper limb muscle activity and physiological responses during computer tasks and recovery periods. Eur J Appl Physiol. 2011;111(11):2791-803, http:// dx.doi.org/10.1007/s00421-011-1908-1.

17. Birch L, Juul-Kristensen B, Jensen C, Finsen L, Christensen $\mathrm{H}$. Acute response to precision, time pressure and mental demand during simulated computer work. Scand J Work Environ Health. 2000;26(4):299-305, http://dx.doi. org/10.5271/sjweh.546.

18. Heiden M, Lyskove, Djupsjöbacka M, Hellström F, Crenshaw AG. Effects of time pressure and precision demands during computer mouse work on muscle oxygenation and position sense. Eur J Appl Physiol. 2005;94(1-2):97-106, http://dx.doi.org/10.1007/s00421-004-1295-y. 
19. Wahlström J, Hagberg M, Johnson PW, Svensson J, Rempel D. Influence of time pressure and verbal provocation on physiological and psychological reactions during work with a computer mouse. Eur J Appl Physiol. 2002;87(3):257-63, http://dx.doi.org/10.1007/s00421-002-0611-7.

20. Ullman J, Kangas N, Ullman P, Wartenberg F, Ericson M. A new approach to the mouse arm syndrome. Int J Occup Saf Ergon. 2003;9(4):463-77.

21. Jensen C, Finsen L, Hansen K, Christensen H. Upper trapezius muscle activity patterns during repetitive manual material handling and work with a computer mouse. J Electromyogr Kinesiol. 1999;9(5):317-25, http://dx.doi.org/10.1016/ S1050-6411(99)00007-3.

22. Lee DL, McLoone H, Dennerlein JT. Observed finger behaviour during computer mouse use. Appl Ergon. 2008;39 (1):107-13, http://dx.doi.org/10.1016/j.apergo.2006.12.008.

23. Kryger AI, Andersen JH, Lassen CF, Brandt LP, Vilstrup I, Overgaard E, et al. Does computer use pose an occupational hazard for forearm pain; from the NUDATA study. Occup Environ Med. 2003;60(11):e14, http://dx.doi.org/10.1136/ oem.60.11.e14.

24. Lassen CF, Mikkelsen S, Kryger AI, Brandt LP, Overgaard E, Thomsen JF, et al. Elbow and wrist/hand symptoms among 6,943 computer operators: A 1-year follow-up study (the NUDATA study). Am J Ind Med. 2004;46(5):521-33, http://dx.doi.org/10.1002/ajim.20081.

25. Won EJ, Johnson PW, Punnett L, Dennerlein JT. Upper extremity biomechanics in computer tasks differ by gender. J Electromyogr Kinesiol. 2009;19(3):428-36, http://dx.doi. org/10.1016/j.jelekin.2007.11.012.

26. Cook CJ, Kothiyal K. Influence of mouse position on muscular activity in the neck, shoulder and arm in computer users. Appl Ergon. 1998;29(6):439-43, http://dx.doi.org/10.1016/ S0003-6870(98)00008-8.

27. Chen HM, Leung CT. The effect on forearm and shoulder muscle activity in using different slanted computer mice. Clin Biomech (Bristol, Avon). 2007;22(5):518-23, http:// dx.doi.org/10.1016/j.clinbiomech.2007.01.006.
28. Oude Hengel KM, Houwink A, Odell D, van Dieën JH, Dennerlein JT. Smaller external notebook mice have different effects on posture and muscle activity. Clin Biomech (Bristol, Avon). 2008;23(6):727-34, http://dx.doi. org/10.1016/j.clinbiomech.2008.01.013.

29. Gustafsson E, Hagberg M. Computer mouse use in two different hand positions: Exposure, comfort, exertion and productivity. Appl Ergon. 2003;34(2):107-13, http://dx.doi. org/10.1016/S0003-6870(03)00005-X.

30. Szeto GP, Lin JK. A study of forearm muscle activity and wrist kinematics in symptomatic office workers performing mouse clicking tasks with different precision and speed demands. J Electromyogr Kinesiol. 2011;21(1):59-66, http:// dx.doi.org/10.1016/j.jelekin.2010.06.006.

31. Japanese Society of Fatigue Science (JSFS). [Visual analogue scale for fatigue] [Internet]. Tokyo: JSFS; 2008 [cited 2013 Nov 10]. Available from: http://www.hirougakkai. com/VAS.pdf. Japanese.

32. Grossman P. Respiration, stress, and cardiovascular function. Psychophysiology. 1983;20(3):284-300, http://dx.doi. org/10.1111/j.1469-8986.1983.tb02156.x.

33. Allen MT, Crowell MD. Patterns of autonomic response during laboratory stressors. Psychophysiology. 1989;26(5): 603-14, http://dx.doi.org/10.1111/j.1469-8986.1989.tb00718.x.

34. Wientjes CJ, Grossman P, Gaillard AW. Influence of drive and timing mechanism on breathing pattern and ventilation during mental task performance. Biol Psychol. 1998;49(1-2): 53-70, http://dx.doi.org/10.1016/S0301-0511(98)00026-X.

35. Carroll D, Turner JR, Rogers S. Heart rate and oxygen consumption during mental arithmetic, a video game, and graded static exercise. Psychophysiology. 1987;24(1):112-8, http://dx.doi.org/10.1111/j.1469-8986.1987.tb01870.x.

36. Ley R, Yelich G. Fractional end-tidal $\mathrm{CO}_{2}$ as an index of the effects of stress on math performance and verbal memory of test-anxious adolescent. Biol Psychol. 1998;49(1-2):83-94, http://dx.doi.org/10.1016/S0301-0511(98)00028-3.

37. Parati G, Mancia G, di Rienzo M, Castiglioni P. Cardiovascular variability is/is not an index of autonomic control of 
circulation. J Appl Physiol. 2006;101:676-82, http://dx.doi. org/10.1152/japplphysiol.00446.2006.

38. Karlqvist LK, Bernmark E, Ekenvall L, Hagberg M, Isaksson A, Rostö T. Computer mouse position as a determinant of posture, muscular load and perceived exertion. Scand J Work Environ Health. 1998;24(1):62-73, http://dx.doi. org/10.5271/sjweh.279.

This work is available in Open Access model and licensed under a Creative Commons Attribution-NonCommercial 3.0 Poland License - http://creativecommons.org/ licenses/by-nc/3.0/pl/deed.en. 